Univerzitet umetnosti u Beogradu,

Odeljenje za Teoriju umetnosti i medija, Beograd

UDK 73/76:004.738.5

73/76:316.774

\title{
SAVREMENA LKKOVNA
}

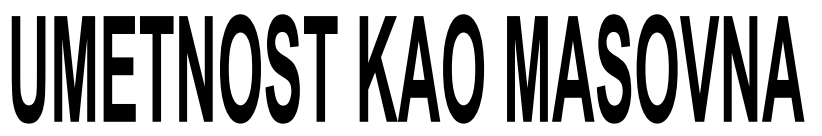

PRAKSA: ZADOVOLSSTVO

ISPOVEDANJAUDGGTALNOJ

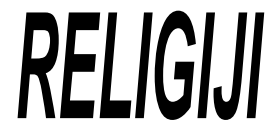

Sažetak: Era masovne produkcije i potrošnje otvara novo polje umetničkog delovanja, kao $i$ stvaranje jednog novog vida 'kreiranja' $i$ 'izlaganja' - internet. Ova digitalna 'demokratska' tvorevina, i ostala savremena tehnologija koja uz nju ide, dostupna je svima, a ne samo umetnicima. Sobzirom da umetnik više nije jedini koji poseduje veštinu, tehnike i znanje, umetnost je ono što umetnik stvara, deli i razmenjuje sa svim drugim ljudima u svakodnevnom životu. Savremena likovna umetnost kao da je postala masovna praksa, a svako umetnik, jer stvara dela svakodnevno i izlaže ih za pogled drugih na popularnim sajtovima. Da li je ovo Bojs predvideo svojom mišlju da je svako umetnik? Proces samo-dokumentacije i ispovedanja preko internet sajtova - digitalne „religije“, je postao masovna opsesija, jer dovodi do dvostrukog zadovoljstva, ali i dvostruke frustracije. Umetnici i drugi ljudi u trci za dokumentovanjem svih aspekata života u strahu od prolaznosti i samoće,

besomučno pokušavaju da ostvare masovnu komunikaciju.

Ključne reči: savremena likovna umetnost, internet, religija, masovna komunikacija, dokumentovanje, reprodukovanje

\section{Uvod}

Početkom 20. veka, umetnost ulazi u eru masovne produkcije i masovne potrošnje. Sa pojavom nove tehnologije i 
mogućnostima brze i lake reprodukcije, umetnost više nije mimetička, niti je viđena kao produžetak umetnikovog tela. Benjamin (Walter Benjamin) je u svojoj knjizi Umetnička dela $u$ doba mehaničke reprodukcije, smatrao da umetnost gubi auru ako izgubi svoj originalni koncept i unikatni izgled. Dišan (Marcel Duchamp), međutim, svojim "readymade" objektima otvara jedno novo polje umetničkog delovanja dozvolivši umetniku ne samo da predstavlja industrijske produkte kao umetnička dela, nego i da oni zadrže svoj industrijski - ne umetnički izgled. Ovo uslovljava da se umetnost približi masovnoj kulturi i da se s njom prepliće.

Umetnički sistem, kao i masovna kultura, teži da obuhvati sve aspekte života, uključujući i religiju, što se još više manifestuje razvitkom tehnologije, mehaničkom proizvodnjom i pojavom digitalnih medija, a naročito interneta. Internet - digitalna 'demokratska' tvorevina i ostala savremena tehnologija koja uz nju ide, dostupna je svima, a ne samo umetnicima. S obzirom da umetnik više nije jedini koji poseduje veštinu tehnike i znanje, umetnost je ono što umetnik stvara, deli i razmenjuje sa svim drugim ljudima u svakodnevnom životu. U današnjem vremenu, umetnost stoga kao da postaje sredstvo masovne komunikacije,

a umetnički sistem deo masovne kulture.

Posle Dišana više ne postoji “ontološka” razlika između stvaranja umetnosti i izlaganja umetnosti, a umetničko delo je ono što se predstavi kao umetničko delo. ${ }^{1}$ Danas najčešće život sam sebe izlaže, a svakodnevica postaje umetničko delo, dok goli život više ne postoji ili je možda postao artefakt. ${ }^{2}$ Proces samodokumentacije i ispovedanja preko internet sajtova - digitalne "religije" - je postao masovna praksa.

Izlaganje života na internetu je masovna opsesija, jer dovodi do dvostrukog zadovoljstva, ali i dvostruke frustracije. Umetnici i drugi ljudi u trci za dokumentovanjem svih aspekata života $\mathrm{u}$ strahu od prolaznosti i samoće, besomučno pokušavaju da ostvare masovnu komunikaciju.

\section{Mehanička reprodukcija, izlaganje i demokratičnost kao masovna komunikacija: od Dišana, preko Pop arta $i$ savremene instalacije prema internetu}

Shvatajući moderno vreme gde industrijska masovna proizvodnja dominira, Dišan razume da umetnost mora da ide $\mathrm{u}$ korak s vremenom (pa nema svrhe više stvarati umetnička dela na tradicionalan način). U vremenu kada rad postaje uslužan rad

1 Groys B., Going Public, e-flux, Inc., Sterberg Press, New York 2010, str. 52.

2 Ibid., 119. 


\section{MILENA POPOV}

(a ne manuelni kao do tada), "ready made umetnost" učestvuje u uređenju društveno političkih odnosa. U duhu avangarde koja je uvek išla ispred svog vremena, Dišan industrijski proizvod izvodi iz originalnog konteksta, prisvaja ga, potpisuje i izlaže kao umetničko delo, ističući da je za umetničko delo najvažnija ideja - ona uvek dolazi prva. Odabrani objekat je samo nosilac te ideje. Umetnik tada prvi put postaje dizajner, nosilac projekta, a nije više bitno ko će "projekat" izvesti. On ovime utire put nastanku konceptualne umetnosti i pomera granice između visoke i niske umetnosti.

Pop art, a posebno Vorholova (Andy Warhol) ličnost i umetnost je približila još više visoku kulturu i masovnu kulturu. Vorhola su levičari okarakterisali kao američkog Bertolda Brehta (Berthold Brecht), a on je sam rekao: "Neko je rekao da je Breht želeo da svi slično misle. Ja želim da svi misle slično. Ali, Breht je na neki način želeo da to ostvari kroz komunizam. Rusija to radi režimski. Ovde se to dešava samo od sebe i bez pritiska vlasti, i nije nužno biti komunista. Svi misle slično i rade slično i sve smo bliži takvom modelu." "3 Vorhol je ovde više imao na umu njegovu poznatu frazu "želim da budem mašina", pa je tako i njegova umetnost upravo vezana za proces produkcije. Prateći tradiciju Dišana, on prepoznaje sredstva i produkte masovne proizvodnje kao estetska, umetnički korisna i neophodna za dalji razvoj umetnosti. Kao i Dišan, on pridaje najveću zaslugu ideji, a ne gotovom produktu: "Trebalo bi da i neko drugi bude u stanju da oslika sve moje slike za mene..." " U njegovom ateljeu Fabrika (Factory), koji je i sam po sebi demokratsko-kapitalistička, pa stoga američka tvorevina, masovno proizvodi umetnost (kao kolektivan rad-proces) da bi više ljudi dobilo dela, govoreći da umetnost treba da bude za svakoga. "Pop-art je za svakoga. I ne mislim da je umetnost namenjena samo upućenima, ona bi trebalo da se obraća masama..."5 Inspirišući se i koristeći sredstva masovne proizvodnje, on stvara umetničke predmete, koji predstavljaju moderne ikone, fetiše, ili kako Betina Funke (Bettina Funcke) kaže: umetnost je transformisana u sinkretičku religiju zabave ili novi opijum za ljude. ${ }^{6} \mathrm{Na}$ ovaj način on pokušava da ostvari san istorijske avangarde - da pretvori stvarnost $\mathrm{u}$ umetnost. ${ }^{7} \mathrm{U}$ svojim printovima, slikama i filmovima na demokratski način tretira kao zvezde i poznate ličnosti poput Merlin Monro (Merilyn Monroe), Elvisa Prislija (Elvis Presley), Džeki Kenedi (Jackie

3 Ren M., Andy Warhol na svoj način, KIZ Art Press, Beograd 1994, str. 66.

4 Ibid., 20.

5 Ibid., 15.

6 Funcke B., Pop or Populus, Sternberg Press New York 2009, str. 178.

7 Funcke B., op. cit.111. 


\section{MILENA POPOV}

Kennedy) i potpuno nepoznate osobe (žrtve automobilskih nesreća, svoje "glumce" i druge). On u Fabrici okuplja mnoštvo nepoznatih ljudi od kojih pravi zvezde, koristeći ih kao modele i glumce u svojim radovima.

Poput Vorhola, koji je mašina što produkuje u Fabrici uz asistenciju brojnih "zvezda", savremeni umetnik stvara često svoja dela u saradnji sa publikom. Publika je sada asistent umetniku ili čak umetnik-saradnik jer ona često sama završava delo. Savremena likovna umetnost tako postaje masovna praksa, a sve češća bijenala, trijenala i slične izložbe kao veliki javni događaji, ali i izlaganje umetničkih dela na internetu, nastaju upravo u želji da se ostvari što veća masovna komunikacija između umetnika i masovne publike.

Umetnik žrtvuje svoja autorska prava radi demokratije, ali sam postaje često artefakt ili "readymade" 8 izlažući svoje telo i svoj život kao umetničko delo. S druge strane, prostor umetničke instalacije nije vezan za lokaciju, niti vreme, te može biti kreiran bilo gde i bilo kad, pa i virtuelno na internetu. U ovom konstantnom mehaničkom reprodukovanju umetničkog dela, ono donekle gubi svoju auru, kao što Benjamin primećuje, ali kreira auru osećanja "ovde i sada". ${ }^{9}$ Ono ne označava separatisanje od sveta i javnog prostora, već jednu deteritorizaciju i dislokaciju društva masovne kulture u kome im omogućava da sami sebe izlože i postanu umetničko delo. ${ }^{10} \mathrm{Na}$ ovaj način savremena likovna umetnost, izlažući samu publiku kao umetničko delo, inspiriše publiku da nastavi izlaganje svojih života sama i van okvira umetnikove instalacije. Popularni internet sajtovi sa mogućnostima lakog rukovanja i raznovrsnim opcijama reprodukcije, manipulacije i izlaganja, postaju plodno tlo za masovnu komunikaciju i novi vid 'kreiranja' i 'izlaganja' ne samo umetnika nego i svih drugih ljudi. Zbog toga se čini da je svako danas umetnik, jer stvara dela svakodnevno (u istom medijumu kao i umetnik) i izlaže ih za pogled drugih. Savremena umetnost tako kao da je postala masovna praksa.

\section{Zadovoljstvo ispovedanja u digitalnoj „,religiji“}

Savremena umetnost se zasniva na 'ideji' ili 'konceptu' a ne 'teškom radu', manuelnom radu, pa je stoga i ideja o umetnosti kao „nematerijalnom radu“11 otvorila put "post-fordističkom' društvu i formiranju jednog virtuelnog prostora - interneta - „digitalnog maoizma“, gde se sve deli i gde ne postoji

8 Groys B., Going Public, e-flux, Inc., Sterberg Press, New York 2010, str. 129.

9 Ibid., 124.

10 Ibid., 125 .

11 Ibid., 124. 


\section{MILENA POPOV}

privatna svojina. ${ }^{12}$ Masovna kultura interneta, poput religije, kreira društva bez zajedničke prošlosti i time otvara mogućnost za dalju modernizaciju. ${ }^{4}$ Kao savremene umetničke izložbe koje posetiocima omogućavaju da budu izloženi i da sami sebe izlože, internet sajtovi poput Facebook-a, korisnicima daju mogućnost da izlože svoj sopstveni život. Ovo izlaganje sopstvenog života podseća ne samo na novomedijsku umetnost arhiviranja, nego i na ispovedanje u religiji. Ako je umetnost, kao što Frojd primećuje, postala zamena za religiju u već laiciranom društvu, sada internet kao novo mesto kreiranja i izlaganja (kao zamena za umetnost) postaje nova zamena za religiju. Upravo u svojim mogućnostima sveobuhvatne masovne komunikacije - mehaničkom repeticijom i reprodukovanjem digitalnih 'nevidljivih' fajlova, izlaganja - ispovedanja života i stvaranjem spektakla, internet neodoljivo podseća na religiju.

Proizvodnja digitalnih videa, fotografija i tekstova je dostupna svakom, te ih svako može vrlo jednostavno praviti i "okačiti", izložiti na internet. ${ }^{13}$ Izgleda da je svako danas umetnik, jer stvara dela (u istim medijumima kao i umetnik) svakodnevno i izlaže ih za pogled drugih na popularnim sajtovima kao što su Facebook, Twitter, Youtube. Danas, tako, život sam sebe izlaže, a svakodnevica postaje umetničko delo, dok goli život više ne postoji ili je možda postao artefakt. ${ }^{14}$ Ovde kao da odjekuje čuvena Hegelova (Friedrich Hegel) misao da je umetnost stvar prošlosti. Proces samodokumentacije ${ }^{15}$ i iznošenja u javnost $\mathrm{u}$ obliku ispovedanja preko internet sajtova je postao masovna opsesija, jer dovodi do dvostrukog zadovoljstva. $\mathrm{S}$ jedne strane, korisnici sajta uživaju u katarzičnom izlaganju svog života (verujući u oslobođenje od strahova i frustracija) i uživanju u svojim minutima slave. Vorhol je šezdesetih godina 20. veka predviđao da će u budućnosti svako imati svojih 15 minuta slave i da se ona kao i harizma može fabrikovati. To vreme slave i fabrikacije je sada uz internet zaista i došlo. Uz bodrijarovski simulakrum i photoshop, svako može biti i izledati kako želi, pa tako npr. u MUDS - "multi-user-dimension-real-time discussion" korisnici sebi stvaraju virtuelne identitete. S druge strane 'posetilac' internet sajtova ima mogućnost da uživa u izloženim životima drugih ljudi i tobožnjem 'ćaskanju' sa ljudima širom sveta - ostvarivanju masovne komunikacije sa milionima drugih korisnika interneta.

12 Lanier J., You Are Not a Gadget: Manifesto, Alfred A. Knopf, New York 2010, str. 12.

13 Umetničko delo se takodje okači na zid galerije, muzeja ili izloži za oko posetioca, gledaoca.

14 Groys B., Going Public, e-flux, Inc., Sterberg Press, New York 2010, str. 119. 15 Ibid., 98. 
Poput savremenih umetničkih dela koja sve više postaju 'vremenska dela', tj. dela kojima je ključna karakteristika dug vremenski period trajanja, repeticija i dokumentovanje (arhiviranje) samog života, 'obični' ljudi u trci za dokumentovanjem svih aspekata života, nemaju vremena da zaista dožive i prožive svoj život. U vremenu smrti boga, vremenu straha od prolaznosti, vremenu globalizacije, demokratije, digitalne reprodukcije i repeticije, internet je postao globalizovana "religija". Ovo svojevrsno mesto hodočašća 'vernici' posećuju svakodnevno i non stop, pogotovo jer ono nije smešteno u posebno određenoj zgradi (poput crkve), već u domu svakog 'vernika' - njegovom intimnom prostoru, a sve više putuje (poput biblije nekada) svud sa njim (preko mobilnih telefona i laptopova). Pred spavanje ljudi se ne mole Bogu pred svojim krevetom, već Facebook-u ili sličnom internet sajtu. Ova nova, digitalna "religija" se umešala u sve pore života, a svoj uticaj zahvaljuje činjenici da većinu svojih čulnih utisaka, ljudi dobijaju preko vida. Spektakl interneta je danas prodro u celovitu realnost, manipulišući svime i pretvarajući sve u spektakl. Ispiranje mozga preko interneta je konstantno poput religijske dogme. Ono doprinosi u velikoj meri globalizaciji - stvaranju uniformne, bezlične mase. Marksistička deviza „Religija je opijum za narod“ bi ovde mogla naći novu primenu.

U realnosti digitalnog matriksa, prostor i vreme su kao i u savremenoj umetnosti ili religijskom zanosu - bezvremeni. Globalizacijom sveta, globalizuje se i 'demokratizuje' i religija, te se ona seli iz duhovnih u javne, profane, čak virtuelne prostore. Digitalni fajlovi upravo svojom kodiranošću, nevidljivošću i nematerijalnošću svog porekla, podsećaju na nevidljive i nematerijalne sakralne mistične poruke, te "digitalna slika funkcioniše kao vizantijska ikona - kao vidljiva reprezentacija nevidljivih digitalnih podataka." ${ }^{16}$ Ova sličnost između religije i digitalnog medija nije spiritualne, već tehničke prirode.

Reprodukovanje i repeticija kao glavne karakteristike interneta, oduvek su bile najvažnije karakteristike svih rituala, a ritual je oduvek bio neizostavna komponenta svake religije. Već je Niče (Friedrich Nietzsche) primetio da je bukvalno, večno ponavljanje jedini način promišljanja besmrtnosti posle smrti boga. Stoga se mehaničko reprodukovanje može smatrati vrstom religijskog rituala. ${ }^{17}$ Benjamin i govori o kapitalizmu kao religiji koja je redukovana na ritual bez teologije. ${ }^{18}$

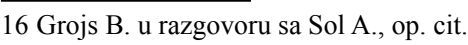

17 Groys B., Going Public, e-flux, Inc., Sterberg Press, New York 2010, str. 145.

18 Benjamin W. The Work of Art in The Age of Mechanical Reproduction, in Illuminations: Essays and Reflections, ed. Hannah Arendt, trans. H. Zohn, Schoocken Books, New York, 1969, str. 221. 


\section{MILENA POPOV}

Internet kao kapitalistička tvorevina koja ima i odlike komunizma, svakako igra ulogu nove, digitalne religije. Nekada su se ljudi ispovedali svešteniku (jednom čoveku, ali Božjem izaslaniku) u crkvama (jedinim, specijalnim mestima za ispovest), a danas se ispovedaju milionima ljudi (bilo kome) na internetu i to ne samo verbalno, već i pisano, uz dodatak brojnih fotografija i videa koji dokumentuju sve aspekte života. U strahu od prolaznosti i samoće, ljudi besomučno pokušavaju da ostvare 'connection'.

Međutim, svačiji život postaje spektakl koji se odvija i gleda gotovo samo na internetu u savremenom deborovskom društvu spektakla. Iako internet zavodi i prisiljava ljude na usredsredenost i aktivnu participaciju, ljudi su pri toj 'aktivnoj participaciji' potpuno izolovani jedan od drugog i od stvarnog života, osuđeni na totalnu pasivnost kao svojevrsnu novu kontemplaciju. Međutim, ova savremena vita contemplativa ne vodi nikakvom rezultatu, niti kao umetnost estetskom sudu, nego samo konstantnom ponavljanju slika. Stoga Debor (Guy Debord) s pravom primećuje da je život postao bioskop, ${ }^{19}$ a Delez (Gilles Deleuze) govori o bukvalnom, mehaničkom ponavljanju kao amoralnom i protivprirodnom. ${ }^{20}$

Iako izlaganje sopstvenog života na internetu donosi ljudima dvostruko zadovoljstvo i svojevrsnu zamenu za religiju, paradoksalno, ono dovodi i do dvostruke frustracije. Ljudi zanemaruju i ne žele da primete početni motiv ovog izlaganja - frustraciju, depresiju zbog otuđenja, kao ni nus produkt ovog izlaganja - ponovnu frustraciju do koje dolazi kada 'gledaoci' ne primećuju, ne obraćaju pažnju na njima ponuđeno izlaganje. 21 U ovom začaranom krugu, želja za prevazilaženjem frustracija od prebrzog tempa života i straha od prolaznosti ostaje konstantna i nezadovoljena. Deborovo Društvo spektakla je predvidelo ovo današnje vreme u kome je brzina života i njegovog ispovedanja u digitalnoj 'religiji' proporcionalna samo još brzini kompjuterske komunikacije. U ovoj novoj 'religiji" sve je instantno, pa tako i dvostruko zadovoljstvo u njoj.

\section{Zaključak}

Kada početkom 20. veka umetnost ulazi u eru brze mehaničke produkcije i reprodukcije, avangardni umetnici poput Dišana ili Vorhola prepoznaju mogućnosti za ostvarenje masovne komunikacije. Oni su ne samo uspeli da prigrabe široku publiku

19 Debord, Guy: The Society of Spectacle, New York 1967, str. 60.

20 Deleuze G., Difference and Repetition, trans. Paul Patton, Continuum, London 2004, str. 23.

21 Groys B., Going Public, e-flux, Inc., Sterberg Press, New York 2010, str. 145. 
koristeći jezik i mehanizme masovne kulture, nego i da pomere granice umetnosti i otvore put stvaranju novih medija kreiranja i izlaganja, poput interneta.

U želji da ostvari masovnu komunikaciju, savremena likovna umetnost postaje masovni događaj u kome publika učestvuje u kreiranju dela, a često i sama postaje izloženo umetničko delo. S druge strane, masovna kultura i njeni konzumenti inspirišu se savremenom umetnošću, a posebno procesom samodokumentacije, odnosno izlaganja života kao umetničkog dela. Internet i savremena tehnologija nisu dostupni samo umetnicima, već svima, te preko njih svako može brzo i lako produkovati i izlagati dela svakodnevno. Upravo ovo kao da nagoveštava Bojs (Joseph Beuys) svojom mišlju da je svako danas umetnik, dok Grojs smatra da je umetnik samo onaj koji profesionalno stvara i izlaže dela, a svi drugi ljudi preko interneta rade to isto samo ne profesionalno. ${ }^{22}$ Tradicionalni odnos između stvaraoca $\mathrm{i}$ gledaoca - potrošača je tako promenjen.

Ono što se danas najčešće izlaže je svakodnevica, te ona samim tim postaje umetničko delo. Popularni "chat" sajtovi postali su opsesivna digitalna "religija" u kojoj ljudi uživaju izlažući svoj život, ispovedajući se svakodnevno i konstantno u strahu od prolaznosti i samoće, besomučno pokušavajući, poput savremene likovne umetnosti, da ostvare masovnu komunikaciju.

\section{LITERATURA:}

Benjamin W., The Work of Art in The Age of Mechanical Reproduction, in Illuminations: Essays and Reflections, ed. Hannah Arendt, trans. H. Zohn, Schoocken Books, New York, 1969

Debord, G., The Society of Spectacle, New York 1967.

Deleuze G., Difference and Repetition, trans. Paul Patton, Continuum, London 2004.

Funcke B., Pop or Populus, Sternberg Press New York 2009.

Grojs B., u razgovoru sa Sol A., promocija knjige Going Public book promotion, NY Art Book Fair, PS1, Njujork 7. november 2010.

Groys B., Going Public, e-flux, Inc., Sterberg Press, New York 2010.

Lanier J., You Are Not a Gadget: Manifesto, Alfred A. Knopf, New York 2010.

Ren M., Andy Warhol na svoj način, KIZ Art Press, Beograd 1994.

22 Grojs B., u razgovoru sa Sol A., promocija knjige Going Public book promotion, NY Art Book Fair, PS1, Njujork 7. november 2010. 


\title{
MILENA POPOV
}

\author{
Milena Popov \\ Beograd University of Art, Interdisciplinary Doctoral Studies - \\ Art and Media Theory Group
}

\section{CONTEMPORARY VISUAL ART AS MASS PRACTICE: PLEASURE IN DIGITAL "RELIGION" CONFESSION}

\begin{abstract}
In the era of mass production and consumption, the emergence of new technologies and opportunities of quick and easy reproduction, Duchamp with his 'readymade' objects opens a new field of artistic activity which has allowed the artist not only to present industrial products as art, but also to keep their industrial, not an artistic look. This allows the creation of a new form of 'creation' and 'exhibition' - Internet which is, as a digital 'democratic' creation and other modern technology that goes with it, available to everyone, not artists only. Given that the artist is no longer the only one who possess the skill and technical knowledge, art is what artist create, share and exchange with other people in everyday life. Contemporary visual art as if became a mass practice. It seems that everyone is an artist today, since everyone creates everyday and exhibits its' creations on popular web sites. Is this what Boys predicted with his thought that everyone is an artist? Life exhibits itself, and everyday life becomes a work of art. Process of self-documentation and its presentation to the public in the form of confession on web sites - the digital "religion" became a mass obsession, because it leads to a double pleasure, even though it leads to double frustration too. In addition to enjoying the cathartic exposure of their life and their minutes of fame, the Internet users also experience double frustration in the misappropriation as the byproduct of this exposure - re frustration that occurs when the 'audience' do not pay attention to the offered exposure. Contemporary visual arts and the Internet are increasingly becoming 'time based' - projects which key feature is long time duration, repetition and documentation (archiving) of life itself. Artists and other people in the race to document all aspects of life, in fear of time passing and loneliness, are desperately trying to achieve mass communication.
\end{abstract}

Key words: contemporary visual arts, Internet, religion, mass communication, documentation, reproduction 